\title{
PLANOS NACIONAIS DE EDUCAÇÃO: ASPECTOS HISTÓRICOS - CRÍTICOS DE SUA TRAJETÓRIA E SEUS DESDOBRAMENTOS NA EDUCAÇÃO BRASILEIRA
}

\author{
Paula Amorin, Maisa Colombo, Gislaine de Oliveira Prodomo Costa, Edilene Cristine Weffort \\ Oliveira, Lucia Maria Corrêa Gomes Ferri.
}

Mestrado em Educação - Universidade do Oeste Paulista - UNOESTE - SP. E-mail: paulaamorin@ig.com.br

\section{RESUMO}

Esta investigação trata do tema, os Planos Nacionais de Educação: um resgate histórico-crítico de sua trajetória e seus desdobramentos na educação brasileira. Buscou-se refletir a importância do planejamento e a implementação das políticas públicas, avaliando a atuação do Estado, e os resultados dos Planos Nacionais de Educação. As políticas públicas vinculam - se a um modelo de Estado e acabam como instrumentos de manutenção de sua configuração no caso, atrelada aos interesses do capital e do mercado. A abordagem metodológica corresponde a uma pesquisa de natureza qualitativa, descritiva, de caráter teórico - crítica, tendo como procedimento de coleta de informação a pesquisa bibliográfica, documental e de legislação. Concluiu-se que as fragilidades ocorridas no planejamento e implementação dos Planos Nacionais de Educação sublinharam-se pelas diretrizes do pós-neoliberalismo em nosso país nas últimas décadas e estiveram sempre num enclave economicista.

Palavras-chave: História da Educação. Políticas Públicas. Planejamento.

\section{INTRODUÇÃO E OBJETIVO}

Este estudo tem como tema os Planos Nacionais de Educação: um resgate histórico-crítico de suas trajetórias e seus desdobramentos na educação brasileira, trazendo uma discussão da problemática relativa ao descompasso entre sua elaboração e implementação. Para abordar a temática em questão, primeiramente refletiu-se o conceito de políticas públicas e planejamento, com foco no resultado do processo político, expressado pela intervenção do Estado.

De acordo com Lamounier (1982, p. 5-21) a compreensão do significado de políticas públicas corresponde a um duplo esforço: de um lado entender a dimensão técnica administrativa que compõe, verificando a eficiência e o resultado prático para a sociedade; e de outro lado reconhecer que toda política pública é uma forma de intervenção nas relações sociais em que o processo decisório condiciona e é condicionado por interesses e expectativas político-sociais.

A participação da sociedade na formulação, acompanhamento e avaliação das políticas públicas, em alguns casos, é assegurada pela própria lei que as institui. No caso da Educação, a sociedade é representada pelos Conselhos: Municipal, Estadual e Nacional. Outros instrumentos para envolver no processo de participação e controle social os diversos segmentos da sociedade 
são: audiências públicas, encontros, conferências e demais instrumentos instituídos pela Constituição Brasileira de 1988.

No entanto, é preciso estar atento ao fato destacado por Oliveira (2006) que, o Brasil, assim como a maioria dos países da América Latina, ainda não conseguiu formar coalizões políticas capazes de equacionar a questão de como desenhar políticas públicas que, ao mesmo tempo impulsionem o desenvolvimento econômico e promovam a inclusão social. Nesse sentido, o objetivo deste estudo foi refletir e discutir criticamente os desafios do planejamento e implementação das políticas públicas, no caso, Planos Nacionais de Educação, considerando as diversas rupturas na história da educação e os fatores sociais, políticos e econômicos.

$\mathrm{Na}$ discussão das políticas educacionais, destaque especial foi dado à questão do planejamento, entendido como um processo que diz respeito a um conjunto de princípios teóricos, procedimentos metodológicos e técnicas que podem ser aplicados para mudança. Vale ressaltar que o planejamento não se refere somente às decisões sobre o futuro, mas questiona o futuro de nossas decisões. Isso porque, não existe planejamento neutro, planejar é priorizar e resolver problemas, o que pressupõe uma determinada visão de mundo, concepção de Estado e de organização social.

Matus (1997, p. 39 a 40)

Não se pode governar eficazmente sem dispor de métodos poderosos de planejamento [...]. O planejamento é uma ferramenta de governo ou uma técnica para o uso dos técnicos? Pode-se e deve-se planejar a política? Precisamos planejar em quaisquer circunstâncias e sob a influência de qualquer ideologia? [...].

Em nosso país, o planejamento tem-se limitado a elaboração de planos e controle, possuindo um caráter controlador de orçamento e alocação de recursos, visando a antecipação do futuro, como se isto fosse racionalmente possível. A atual política educacional é parte do projeto de reforma que, coloca os custos com as políticas educacionais no centro da crise do Estado. Nesse projeto de reforma, o Estado busca racionalizar recursos e diminuir seu papel no que se refere ás políticas sociais em geral e às políticas educacionais em particular.

\section{METODOLOGIA}

Esta investigação fez uso da metodologia qualitativa, por meio de uma análise crítica das políticas públicas no enclave do processo político.

Bogdan (1994, p. 16) 
Utilizamos à expressão investigação qualitativa como um termo genérico que agrupa diversas estratégias de investigação que partilham de determinadas características. [...] As questões a investigar não $s$ estabelecem mediante a operacionalização de variáveis, sendo, outrossim formulados com o objetivo de investigar os fenômenos em toda sua complexidade e em contexto natural.

Abordou-se o planejamento e a implementação dos Planos Nacionais de Educação no Brasil por meio de um estudo descritivo, com eixo teórico-crítico, que utiliza o procedimento de coleta, pela fonte de informação bibliográfica, documental e legislação.

\section{RESULTADOS}

A História da Educação em nosso país é marcada por grandes rupturas desde a chegada dos colonizadores em 1500, até o período que abrange a Colônia, Império e República (1930); período considerado pouco relevante para a economia, em que o Brasil atuava apenas como exportador de açúcar, café e borracha e, em relação à educação, pouco se fez.

Conforme Romanelli (1999, p.36),

[...] inúmeras foram às dificuldades daí decorrentes para o sistema educacional. Da expulsão até as primeiras providências para a substituição dos educadores e do sistema jesuítico transcorreu um lapso de 13 anos. A expulsão dos jesuítas desmantelou toda uma estrutura administrativa de ensino.

Na década de 1930, Getúlio Vargas criou o Ministério da Educação e Cultura e na sequência, o Conselho Nacional de Educação, com a proposta de elaboração de um plano nacional de educação, que objetivasse o desenvolvimento socioeconômico do país, diminuindo os níveis de desemprego, pobreza e desigualdade (FERREIRA, 2011).

Foi somente em 1932, por meio do Manifesto dos Pioneiros e da Educação Nova, que se reivindicou a criação de um sistema que organizasse a educação conforme a demanda do país.

A Constituição de 1934 previa um Plano Nacional de Educação (PNE) que garantisse o ensino primário gratuito e obrigatório. Esse PNE era entendido pelos educadores como algo renovador, que agregava diversos benefícios aos cidadãos através de políticas educacionais. Porém em 1937, a proposta de transformar o PNE em lei não se concretizou; neste período de instauração do Estado Novo (1937 - 1945), o planejamento dava suporte ao objetivo econômico do governo, caracterizado por uma divisão da educação para elite, para mulher e para os 
trabalhadores, estabelecendo-se, assim, como função o suporte ao projeto industrial do governo. (ROMANELLI, 1999).

Entre 1946 e 1962, o Plano Nacional de Educação (PNE) foi marcado por duas visões para a construção do projeto de elaboração da Lei de Diretrizes e Bases (LDB). Enquanto a primeira tendência salientava a necessidade da construção de um sistema de ensino voltado para o desenvolvimento brasileiro, a segunda visão dava às famílias o direito de decidir sobre o tipo de educação dos filhos. Nessa discussão, acabou por prevalecer à segunda visão.

Promulgada a Lei de Diretrizes e Bases no 5692/61 (LDB), referindo-se ao Planejamento da Educação, reduzia-se à instrumentalização de distribuição de recursos destinados à manutenção e desenvolvimento do sistema público de ensino em seus diferentes níveis. No governo de Kubitschek (1956 - 1961), o planejamento continuou com a dimensão desenvolvimentista do Estado Novo.

Apesar de, durante os governos democráticos de Goulart e Kubitschek ocorrerem grandes mobilizações dos educadores em fóruns nacionais para discutir o sistema educacional, a educação continuava com forte enclave desenvolvimentista. Nas metas decenais para a educação, também, na América Latina estava presente o enfoque econômico. No ano de 1961 promulgou-se a primeira Lei de Diretrizes e Bases e implementou-se em 1962/1963, os primeiros planos educacionais. No período de 1962 até 1985, ocorreram significativas mudanças no cenário político e educacional, transformando a educação em mero instrumento de racionalidade tecnicista, sem qualquer interferência ou participação da sociedade no processo ou sistema de educação, o que acabou por reduzir a tarefa do professor a de executor de tarefas.

Os esforços de Anísio Teixeira refletiam a resistência nacional quanto às metas internacionais; o Conselho Federal de Educação elaborou o primeiro Plano Nacional de Educação (PNE), dispondo sobre a aplicação de recursos federais para a educação, numa tentativa de adaptar as metas ao contexto brasileiro. No período do golpe militar, o planejamento educacional foi transferido dos educadores para os tecnocratas, com um viés economicista, voltado para os interesses internacionais, influenciado pelos interesses capitalistas e enfatizava a obrigatoriedade da educação profissional, ficando subordinado ao Ministério do Planejamento, os recursos para a educação sequer foram citados na Constituição de 1967. Na década de 80, com o fim do regime militar, a sociedade iniciou uma tentativa de movimento através de fóruns, de caráter democrático e participativo. O país passa pela elaboração do I Plano Nacional de Desenvolvimento 
da Nova República (PND), utilizando como suporte, o Plano de Educação para Todos na formulação de políticas, planejamento e gestão democrática.

Estranhamente, na década de 1990, o Ministério da Educação se coloca em segundo plano quanto ao ensino profissionalizante, cedendo lugar ao Ministério do Trabalho que, articulado com a sociedade criou, o Plano Nacional de Educação Profissional (PLANFOR-1995/2003), cujo objetivo era dar assistência aos grupos que apresentassem dificuldades em manter um vínculo empregatício, consequentemente, sem renda familiar. No período de 2003 a 2010, foi criado o Plano de Ações Articuladas (PAR), com a finalidade de viabilizar a autonomia institucional e a qualidade da educação brasileira. Persistiram os problemas de falta de docentes, baixos salários, prédios improvisados, falta de material didático.

\section{DISCUSSÃO}

Atualmente, no Brasil, está em fase de votação no Congresso Nacional, um novo Plano Nacional de Educação (PNE), em tramitação no Senado desde 2011. Se aprovado, abrangerá o período de 2013 a 2020. Isso significa que estamos sem um Plano Nacional de Educação (PNE) vigente. Os temas abordados por este novo Plano Nacional de Educação (PNE) são diversos e contemplam todos os níveis de ensino desde creche, alfabetização, até pós-graduação. O projeto foi enviado pelo governo federal ao Congresso Nacional em 15 de dezembro de 2010 e foi aprovado pela Câmara dos Deputados em outubro de 2012 depois de ter recebido cerca de três mil emendas.

A ampla abrangência deste Plano Nacional de Educação (PNE) se deve ao fato de o Brasil ainda enfrentar as mesmas dificuldades em relação a questões antigas como: o alto índice de analfabetismo. São 12,9 milhões de pessoas, acima dos 15 anos, analfabetas segundo o relatório de 2012 da Pesquisa Nacional por Amostra de Domicílios (PNAD), organizada pelo Instituto Brasileiro de Geografia e Estatística (IBGE), com base em dados de 2011. As dificuldades enfrentadas pelos professores em alfabetizar as crianças na idade certa. Dados levantados pelo Censo de 2010 revelaram que, aproximadamente 15,2\% das crianças brasileiras em idade escolar não sabem ler e escrever. Além da evasão escolar. Segundo dados do Instituto Nacional de Estudos e Pesquisas Anísio Teixeira (INEP), em 2007, de cada 100 alunos que ingressaram no 10 ano do Ensino Fundamental, apenas 05 concluíram o 9a ano.

Além das questões mencionadas acima, vários outros desafios estão postos ao Plano Nacional de Educação (PNE), em trâmite no Congresso Nacional, dentre os quais merecem 
destaque: formação e valorização profissional, qualidade social, Plano de Estado e Sistema Articulado, gestão democrática, financiamentos e diversidades (FERNANDES, 2011). Conforme aponta o autor, diante das perspectivas de ação colocadas a este novo Plano Nacional de Educação (PNE/2011-2020), a necessidade da participação da sociedade brasileira parece clara, pois, uma educação de qualidade é de interesse de todos os cidadãos.

\section{CONCLUSÃO}

A educação brasileira sempre esteve em descompasso em relação à maioria dos países desenvolvidos e desvinculada, dos demais setores da sociedade e dos avanços da própria concepção de planejamento. As ações dissociam-se do planejado na medida em que, planeja-se o que não se faz e faz-se o que não se planeja. O resultado é evidente: a acumulação angustiante dos problemas e a incapacidade dos governos para manejar seu balanço de gestão pública.

O Brasil é um país que, ao longo de todo o seu processo histórico sempre foi marcado por exclusões no cenário social, sendo estas, um dos principais problemas do sistema educacional. A partir das características levantadas no trajeto histórico da educação no Brasil, conclui-se que os atrasos e progressos ocorridos no planejamento e implementação dos Planos Nacionais de Educação estiveram sublinhados pelas diretrizes neoliberais.

No entanto, a recuperação do Estado como planejador pode ser considerada positiva na medida em que vislumbra a possibilidade de organização do sistema nacional de educação, por outro lado, destaca-se a complexidade do quadro com a presença de fortes antagonismos na condução do Estado brasileiro que, acabam interferindo na forma precária em que o planejamento e a implementação das políticas educacionais são conduzidos, configurando-se num desdobramento do baixo investimento financeiro e político na educação brasileira (FERREIRA, 2011).

É preciso considerar que, a luta por uma educação democrática no Brasil ainda é uma aspiração, e que a sociedade brasileira precisa se mobilizar em seu favor, pois, conforme aponta Lima (2010), a justiça social e os processos de não exclusão resultam de conquistas da própria sociedade e não são resultantes de medidas outorgadas. O autor ressalta ainda que, tais conquistas são efetivadas por meio de uma contra - internalização propiciada pela educação, por meio de uma emancipação concreta da sociedade e do homem e que, somente assim, será possível "reunir a dimensão necessária de emancipação, libertação, justiça social, humanização e universalização das construções sociais, rompendo definitivamente com o ordenamento da teoria 
do sociometabolismo do capital, na atualidade, sob a denominação de neoliberalismo". (LIMA, 2010, p.12).

Conforme aponta Peroni (2007), é necessário estar atento à falsa ideia de que a sociedade civil participa do processo político por meio de suas instituições representativas, como sindicatos, movimentos sociais e partidos, pois, estes, na realidade estão sendo neutralizados como parte da estratégia pós-neoliberal.

O planejamento deve ser o instrumento da sistematização da educação no Brasil; o Estado deve garantir as possibilidades financeiras, gestão democrática e a qualidade, supervisionando e avaliando a implementação do Plano Nacional de Educação (PNE) e a articulação das políticas públicas sociais.

\section{REFERÊNCIAS}

AFONSO, S. R. Reflexões sobre o Estado, Políticas Públicas e Educação. Disponível em: http://www.artigonal.com.br/educacao-artigos/reflexões-sobre-estado-politicas-publicas-eeducacao-1223016.html. Acesso: em 08 de agos. de 2013.

BOGDAN, R.; BIKLEN, S. Investigação qualitativa em educação. Porto: Porto Editora, Ltda., 1994, p. 183-93.

FERNANDES, F. das C. Perspectiva para o novo Plano Nacional de Educação - PNE (2011-2020). In SOUZA, J. (org). Políticas de gestão e práticas educativas: a qualidade do ensino. Brasília: Liber, 2011. p. 81-94.

FERREIRA, E.B.; FONSECA. M. O planejamento das políticas educativas no Brasil e seus desafios atuais. Florianópolis: Perspectiva, v. 29, n. 1, jan./jun.2001. p. 69-96.

LAMOUNIER, B. Análise de políticas públicas: quadro teórico-metodológico de referência. In: FUNDAP. Planejamento e políticas públicas. São Paulo: Fundação do Desenvolvimento Administrativo - FUNDAP, 1982. p. 5-21.

LIMA, P. G.; ARANDA, M. A. de M.; LIMA, A. B. de. Estado, Políticas Educacionais e gestão democrática da escola no Brasil. In: ENDIPE - Encontro Nacional de Didática e Prática de Ensino. Convergências e tensões no campo da formação e do trabalho docente: políticas e práticas educacionais. Belo Horizonte, 2010, UFMG, Belo Horizonte - MG, 2010, p. 01-37.

MATUS, C. Adeus, Senhor Presidente. Coleção Ciências Técnicas de Governo. Edições FUNDAP,São Paulo,1996.

OLIVEIRA, J. A. P. Desafios do planejamento em políticas públicas: diferentes visões e práticas. RAP. Rio de Janeiro. Março/Abril 2006. 
Encontro de Ensino, Pesquisa e Extensão, Presidente Prudente, 21 a 24 de outubro, 2013

PERONI, V. M. V. Reforma do Estado e a tensão entre o público e o privado. In: Revista SIMPE RS, Porto Alegre, 2007. p. 11-33.

ROMANELLI, O. História da educação no Brasil: 1930-1973. Petrópolis: Vozes, 1999. 